\title{
Entomophthora Conidia in the Air-spora
}

\author{
By N. WILDING \\ Rothamsted Experimental Station, \\ Harpenden, Hertfordshire \\ (Accepted for publication 18 April 1970)
}

SUMMARY

\begin{abstract}
At Silwood Park, Berkshire, in I958, the largest concentration of each of five 'types' of Entomophthora conidia in the air typically occurred at 05.00 to $07.00 \mathrm{~h}$. and was associated with humid air and sunrise. The smallest concentration occurred between I 4.00 and I7.00 h. when the air was usually driest.
\end{abstract}

\section{INTRODUCTION}

Lacey (1962) operated a Hirst automatic volumetric spore trap at Silwood Park, Berkshire, from May to September $195^{8}$, in a sheltered site near a stream and in an exposed site, and estimated the daily concentration of pollen grains and fungus spores in the air. She did not publish her figures for Entomophthora conidia but found most at the sheltered site during late June and July (personal communication). I have re-examined in detail Lacey's spore trap slides that were made during this time at the sheltered site and have classified the Entomophthora conidia into five types, determining the diurnal periodicity of each. I then compared my findings with those of Hamilton (1957, 1959), who used a Hirst spore trap to estimate the aerial concentration of pollen grains, fungus spores and organic and inorganic particles at $2 \mathrm{~h}$. intervits and who attempted to correlate her results with weather records. Hamilton's studies wre done: (I) in 1954 at South Kensington, London, when most Entomophthora coi ydia were recorded during August and September; (2) in I954 at Rothamsted, Hertfordshire, a rural site, when conidia were abundant throughout July and August; (3) in I955 at South Kensington when conidia were most numerous during August and September, as in 1954 (Hamilton, 1957). She found a diurnal periodicity of occurrence of Entomophthora conidia with maxima at 05.00 and I3.00 h. That at $\mathrm{I} 3.00 \mathrm{~h}$. when the air is usually relatively dry, is unexpected since spore discharge occurs only when the relative humidity exceeds $90 \%$ (Rockwood, r950; Wilding, 1969). However, Hamilton counted small numbers of Entomophthora conidia which may have shown peaks that were not significant, or the bimodal periodicity might have been caused by differences between species all grouped together by Hamilton as Entomophthora.

\section{METHODS}

On each slide, from 25 June to 24 July, roo $\mu \mathrm{m}$. wide short traverses (Hirst, I953) were scanned at $2 \mathrm{~mm}$. intervals corresponding to each hour. Assuming that Lacey's trap was $100 \%$ efficient, each conidium counted was equivalent to an aerial concentration of 33 conidia $/ \mathrm{m}^{3}$. 
Conidia were segregated into one of five types distinguished as follows: Entomophthora aphidis type conidia were ovoid with a rounded papillate base. They were $\mathrm{I} 5$ to $30 \mu \mathrm{m}$. long $\times 7$ to I $4 \mu \mathrm{m}$. wide, commonly asymmetrical and are included in Lakon's papillata and subpapillata types (Lakon, 1919). Entomophthora echinospora type conidia were ovoid, like those of the $E$. aphidis type, but less variable in size, approximately $20 \mu \mathrm{m}$. long $\times 12 \mu \mathrm{m}$. wide, usually symmetrical and with a truncate papilla. They are included in Lakon's subpapillata and truncata lageniformis types. Entomophthora grylli type were roundly ovoid, about $20 \mu \mathrm{m}$. long $\times$ I $5 \mu \mathrm{m}$. wide, with a prominent truncate papilla. They are of Lakon's truncata lageniformis type. Entomophthora muscae type were helmet-shaped with a broad flat base and pointed apex which could be seen only when the conidium was resting in a certain plane on the trapping medium. They were I 5 to $20 \mu \mathrm{m}$. long and I 4 to $\mathrm{I} 8 \mu \mathrm{m}$. wide and form Lakon's truncata campaniformis type. Entomophthora sphaerosperma type were cigar-shaped, about $16 \mu \mathrm{m}$. long $\times 7.5 \mu \mathrm{m}$. wide, with a broadly papillate base and rounded apex. They fall into Lakon's papillata type.

Weather. Hourly records of temperature, humidity, rainfall and sunshine were taken from the meteorological enclosure at Silwood Park, about $400 \mathrm{~m}$. from the trapping site where it was probably more humid (Lacey, 1962). Records of wind speed, wind direction and gustiness were for the Air Ministry Meteorological Office at South Farnborough, $14 \mathrm{~km}$. south-west of Silwood Park.

Table I. Number of Entomophthora conidia in the air

\begin{tabular}{|c|c|c|c|c|c|}
\hline \multirow[b]{2}{*}{ Source } & \multirow[b]{2}{*}{ Reference } & \multicolumn{2}{|c|}{$\begin{array}{c}\text { Conidia* } \\
\text { concentration } / \mathrm{m} .{ }^{3} / \mathrm{h} \text {. }\end{array}$} & \multicolumn{2}{|r|}{ Sample } \\
\hline & & Av. & Max. & Date & Area \\
\hline Present results & - & I I4 & 2964 & $\begin{array}{l}25 . \text { vi. } 58- \\
24 \text {. vii. } 58\end{array}$ & \multirow{3}{*}{$\begin{array}{l}\text { Silwood Park } \\
\text { (sheltered site) }\end{array}$} \\
\hline \multirow[t]{3}{*}{ Lacey } & \multirow[t]{3}{*}{1962} & 127 & - & $\begin{array}{l}25 . \text { vi. } 58- \\
24 \text {. vii. } 58\end{array}$ & \\
\hline & & 36 & - & $\begin{array}{l}\text { 14. v. } 5^{8-} \\
25 . \text { ix. } 5^{8}\end{array}$ & \\
\hline & & 5 & - & $\begin{array}{l}\text { I4. v. } 58- \\
25 . \text { ix. } 5^{8}\end{array}$ & $\begin{array}{l}\text { Silwood Park } \\
\quad \text { (exposed site) }\end{array}$ \\
\hline \multirow[t]{3}{*}{ Hamilton } & \multirow[t]{3}{*}{1957} & 22 & 560 & $\begin{array}{l}\text { 4. v. } 54- \\
\text { 30. ix. } 54\end{array}$ & Rothamsted \\
\hline & & 19 & 400 & $\begin{array}{l}\text { 4. v. } 54- \\
\text { 30. ix. } 54\end{array}$ & \multirow{2}{*}{ South Kensington } \\
\hline & & 10 & 320 & $\begin{array}{l}\text { I. v. } 55^{-} \\
\text {30. ix. } 55\end{array}$ & \\
\hline
\end{tabular}

\section{RESULTS}

Figure I shows the estimated average concentration of Entomophthora conidia $/ \mathrm{m}^{3}$ in the air for each $24 \mathrm{~h}$. period 09.00 to $09.00 \mathrm{~h}$. from June to September 1958, found by Lacey and based on a single longitudinal trace of each slide. Conidia were not caught before 26 June and most were caught from then until 24 July, a relatively warm dry period in an otherwise cool damp year. Conidia were then trapped infrequently at intervals during the rest of the summer. Figure $I$ also shows my estimates, from 25 June to 24 July for the same $24 \mathrm{~h}$. periods, which were based on the numbers found in 24 


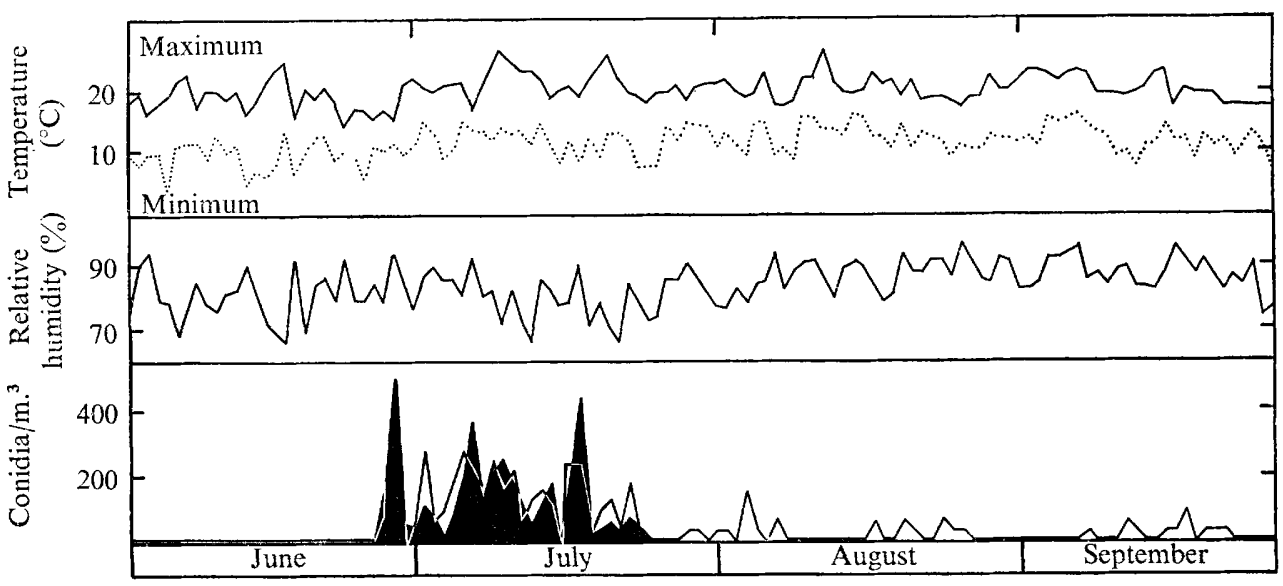

Fig. I. Seasonal change in weather and abundance of Entomophthora conidia in the air-spora. Line-based on daily counts; shaded area-based on hourly counts from 25 June to 24 July only.

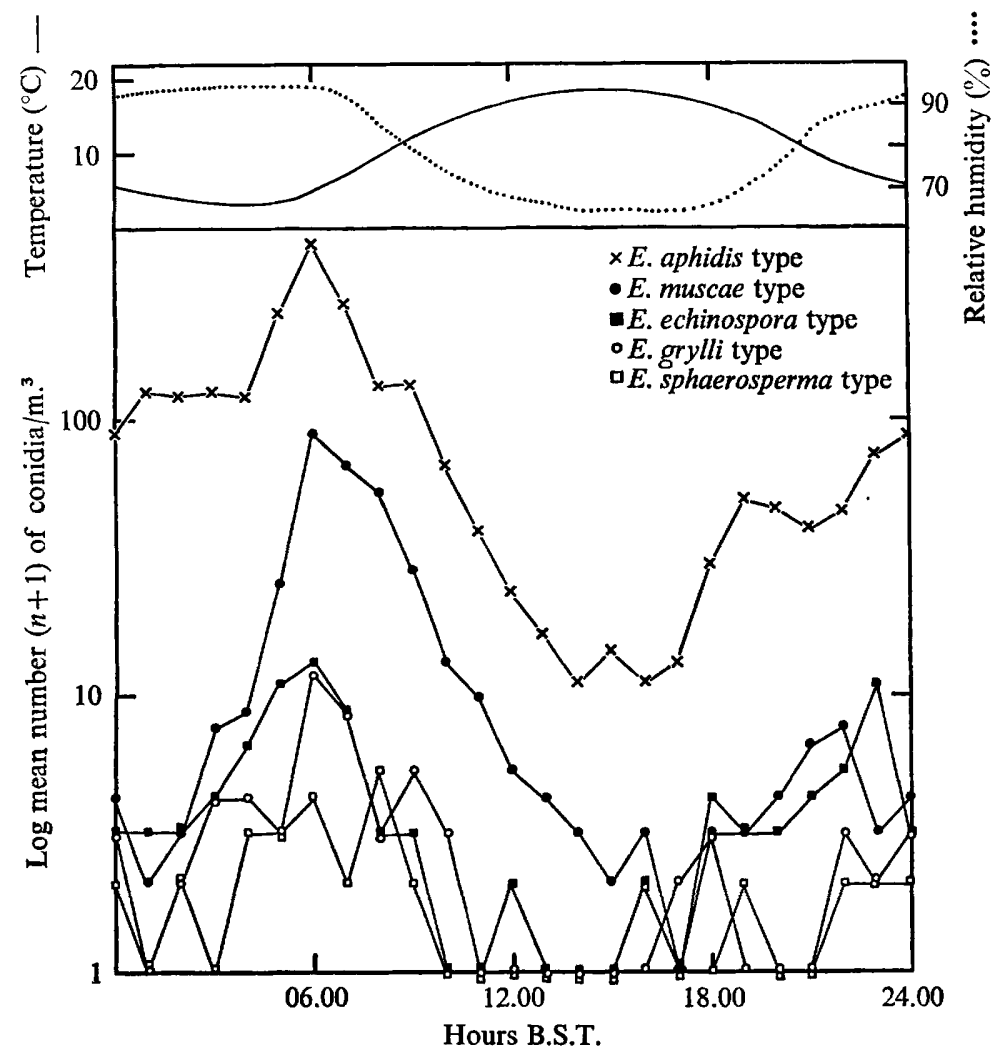

Fig. 2. Mean diurnal periodicity of different Entomophthora conidial 'types' and the mean variations in temperature and relative humidity. 25 June to 24 July. 


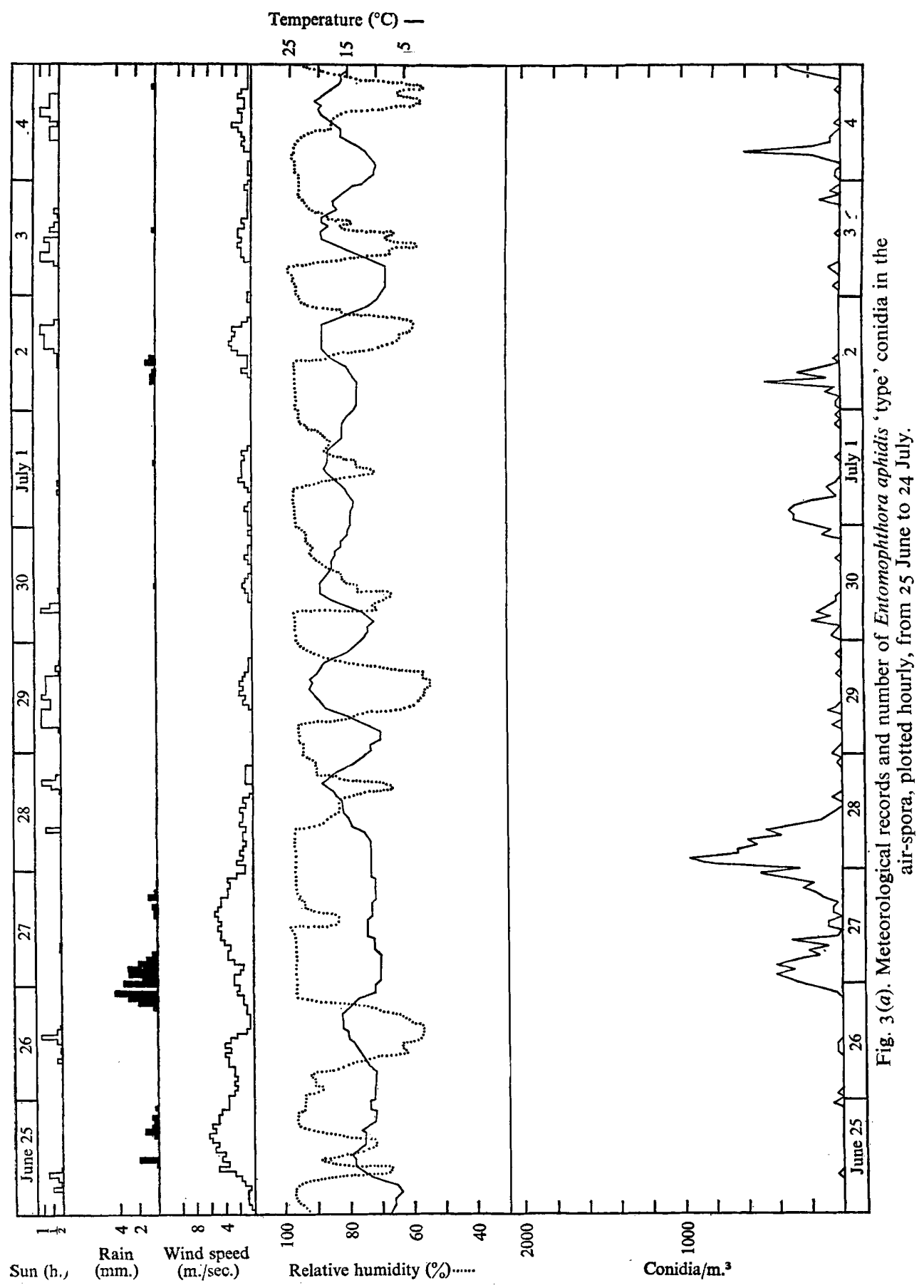




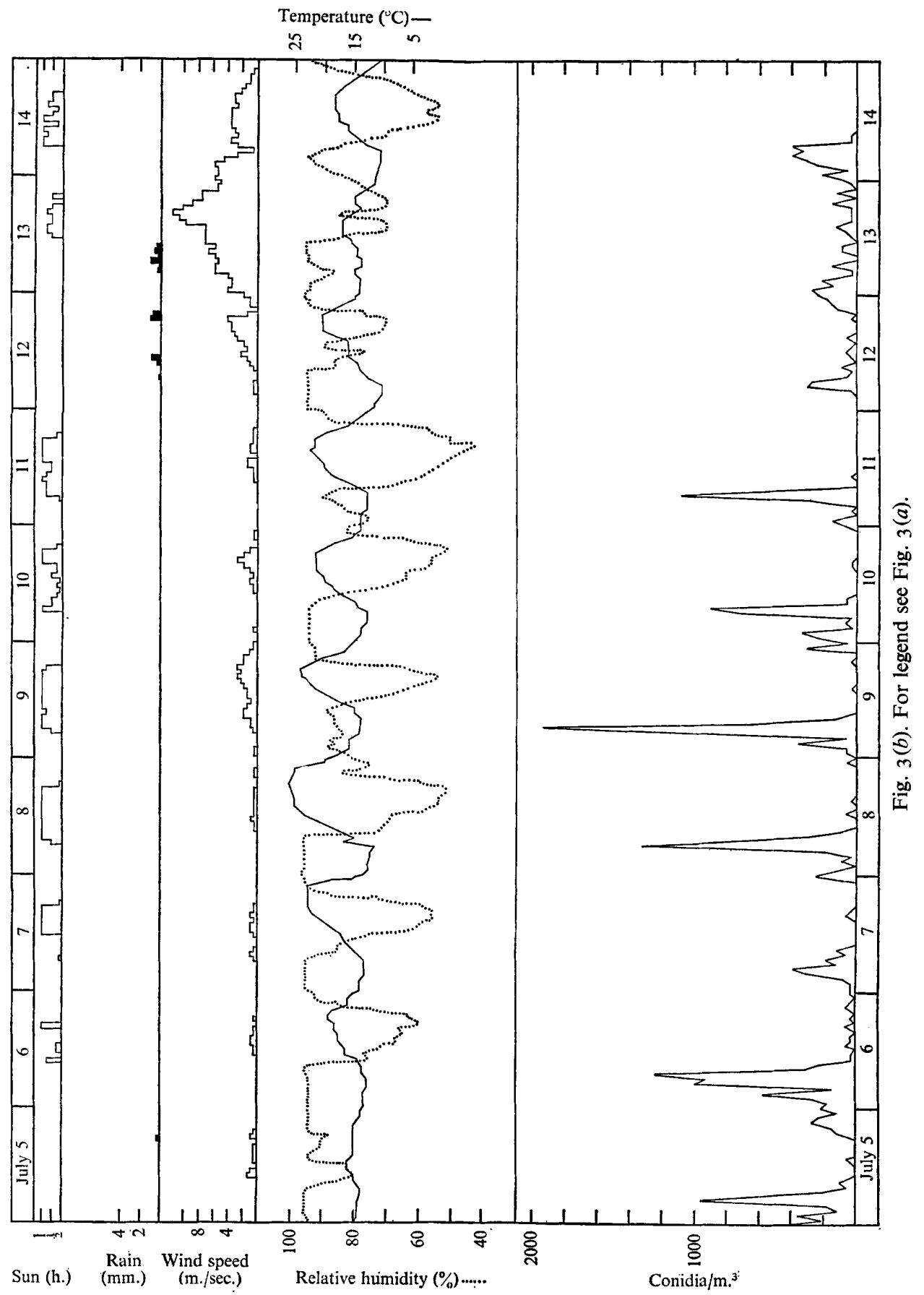




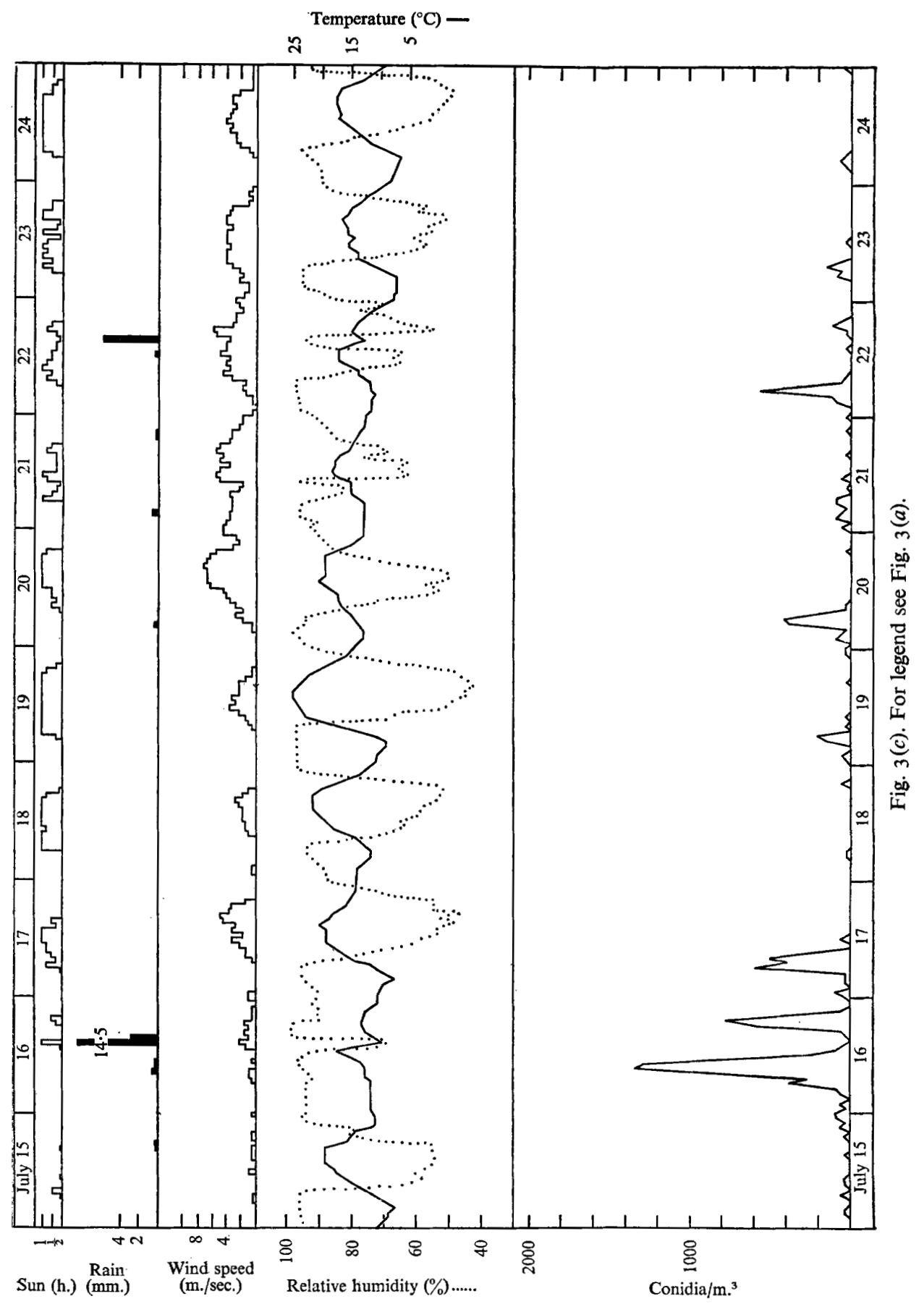


transverse traces of the same slides. The daily totals of conidia obtained by the two scanning methods were similar. Table I compares my estimates of the average and maximum concentrations of conidia with those of Lacey (1962) and Hamilton (1957).

During the study period, Entomophthora aphidis type conidia, of which more than four times as many were caught as of the other types together, and E. muscae type conidia were the most abundant. All the types exhibited the same diurnal periodicity (Fig. 2).

Conidia were most abundant when the air was cool and humid, typically around dawn (Fig. 2), but also when the relative humidity was high later in the day; for example, between 08.00 and $12.00 \mathrm{~h}$. on 16 July (Fig. $3 c$, Entomophthora aphidis type). Peak numbers of conidia correspond with unusually prolonged periods of high humidity (Fig. 3).

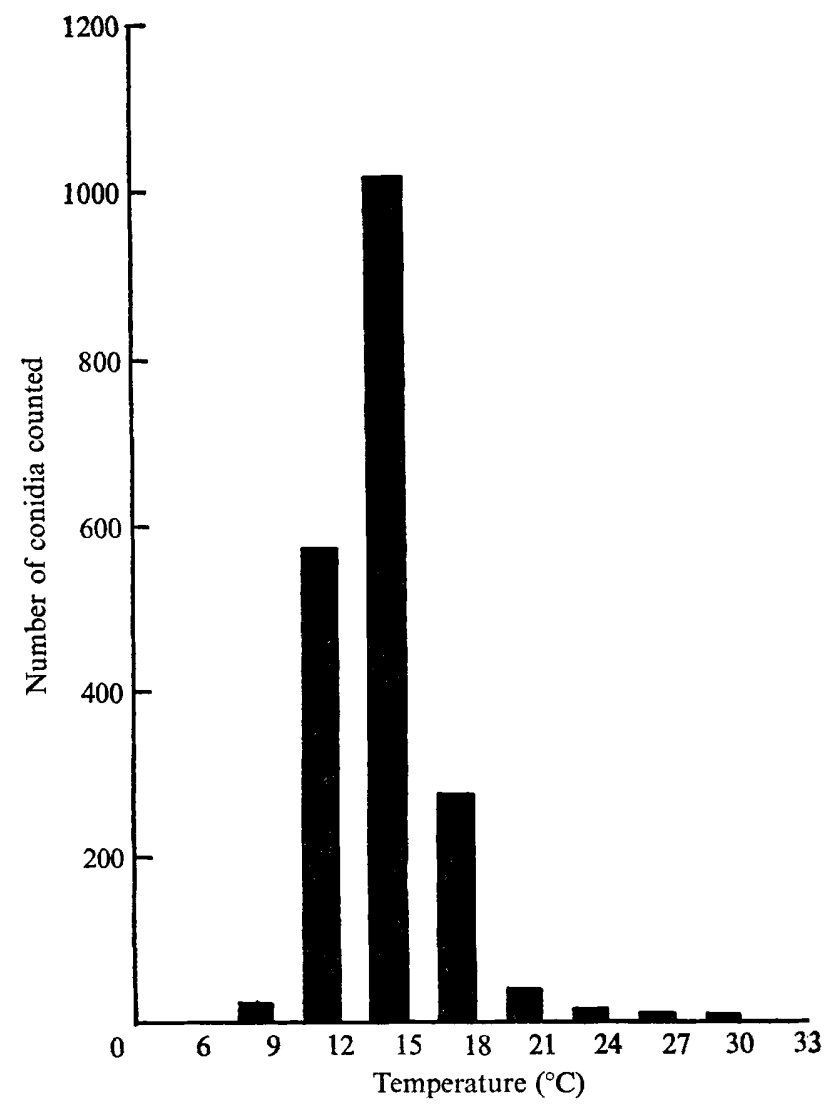

Fig. 4

Conidia were most numerous between 13 and $15^{\circ}$ and were rarely caught below $10^{\circ}$ or above $21^{\circ}$ (Fig. 4).

Wind speeds were consistently fastest during the day and thus, as humidity was small during the day (Fig. 2), conidia were most numerous when winds were slowest. There was no correlation between conidial numbers and either rain or sunshine. Hamilton, too, found no correlation with sunshine but she found that concentrations were significantly smaller during rainfall. 


\section{DISCUSSION}

All the recorded types of Entomophthora conidia exhibited a similar diurnal periodicity with a peak at $06.00 \mathrm{~h}$. and with fewest in the air between 14.00 and $17.00 \mathrm{~h}$. Thus, although this agrees with Hamilton's (1959) record of an early morning peak, I find neither evidence of a second peak at $13.00 \mathrm{~h}$. nor any indication that a second peak could be caused by different species exhibiting differences in diurnal periodicity.

The correlation between conidial numbers and humidity observed by Hamilton (1959) and Rockwood (1950) was confirmed and is as expected from results of laboratory experiments (Wilding, I969). Conidia were caught when the relative humidity, as recorded by the meteorological station, was less than the minimum for conidial discharge in Entomophthora species but the trapping site was probably more humid than the meteorological enclosure; also, the humidity at the sporulating surface is probably more than, though proportional to, that of the surrounding air (Wilding, 1969). Figure 2 shows that the hourly average concentration of $E$. aphidis type conidia remained constant from 01.00 to $04.00 \mathrm{~h}$. and then rose at $06.00 \mathrm{~h}$. to a value four times that at $04.00 \mathrm{~h}$. This peak when humidity is very little more than for the preceding hours may be explained by the influence of light at sunrise on sporulation. Ege (1965) showed that cultures of E. coronata, E. virulenta and one other Entomophthora species (probably E. thaxteriana), on artificial media, discharged from $\mathrm{I} \cdot 5$ to Io times as many conidia in light as in dark, and Callaghan (I969) showed that, when cultures of $E$. coronata were subjected to a $12: \mathrm{I} 2 \mathrm{~h}$. alternation of light and dark, within an hour of each admission of light, conidial discharge increased to about five times that in the dark.

Airborne conidia were most numerous between $\mathrm{I} 3$ and $\mathrm{I} 5^{\circ}$, and the average number of conidia for each hour of the day was inversely correlated with the corresponding temperature. However, in 1955, Hamilton (1959) found most conidia between 18 and $20.5^{\circ}$, and Ege (1965) showed in laboratory experiments that the optimum temperature for conidial discharge by cultures of Entomophthora species on artificial media was $20^{\circ}$. During the study period, temperature and humidity were inversely correlated and the temperature did not exceed $\mathrm{I} 8^{\circ}$ when the relative humidity exceeded $85 \%$. But conidial discharge of Entomophthora species occurs only in a near saturated atmosphere (Wilding, 1969), probably irrespective of the temperature. Thus conidia were most abundant below the optimum temperature for their discharge, found by Ege (1965), probably because at that temperature the relative humidity was rarely enough for discharge.

Hamilton (1959) suggested that strong winds decreased the number of insect hosts and consequently the number of Entomophthora conidia, but Hamilton and I probably found fewer conidia in strong winds because humidity was inversely correlated with wind speed.

Studies in England (Hamilton, 1957, 1959; Lacey, 1962) show that the largest numbers of Entomophthora conidia in the air are caught at some time between July and September when insect populations are largest. My observations suggest that, within that period, aerial concentrations of conidia are related to weather, especially the relative humidity. Conidial discharge will increase with increased temperature up to $20^{\circ}$ and will be more in light than in dark only when the air remains humid. Near saturation is most usual from or $.00 \mathrm{~h}$. but the greatest aerial concentrations of conidia are typically not reached until sunrise. They then remain abundant until $07.00 \mathrm{~h}$. when the relative humidity falls. 
I am indebted to Mrs E. Goodhew (née Hamilton) for permission to quote from her Ph.D. Thesis, to Mrs M. E. Lacey for permission to publish her values for the daily concentration of Entomophthora conidia, and to Imperial College Field Station and the Meteorological Office, Bracknell, for the meteorological data.

\section{REFERENCES}

Callaghan, A. A. (1969). Light and spore discharge in Entomophthorales. Transactions of the British Mycological Society 53, 87-97.

EGE, O. (1965). Ein Beitrag zur Biologie einiger aphidovorer Entomophthoraceen. Archiv für Mikrobiologie 52, 20-48.

Hamilton, E. D. (1957). A Comparison of the Pollen and Fungus Spore Content of the Air in Two Localities as a Contribution to the Study of Respiratory Allergy. Ph.D. Thesis, University of London.

Hamilton, E. D. (1959). Studies on the air-spora. Acta Allergologica 13, 143-175.

Hirst, J. M. (1953). Changes in atmospheric spore content: diurnal periodicity and the effects of weather. Transactions of the British Mycological Society 36, 375-393.

LACEY, M. E. (1962). The summer air-spora of two contrasting adjacent rural sites. Journal of General Microbiology 29, 485-50I.

LaKon, G. (1919). Die Insektenfeinde aus der Familie der Entomophthoreen. Zeitschrift für Angewandte Entomologie 5, 161-216.

Rockwood, L. P. (1950). Entomogenous fungi of the family Entomophthoraceae in the Pacific Northwest. Journal of Economic Entomology 43, 704-707.

WILDING, N. (1969). Effect of humidity on the sporulation of Entomophthora aphidis and E. thaxteriana. Transactions of the British Mycological Society 53, 126-130. 